\title{
Synergistic Activity of Ceragenins Against Carbapenem-Resistant Acinetobacter baumannii Strains in Both Checkerboard and Dynamic Time-Kill Assays
}

\author{
Cagla Bozkurt-Guzel ${ }^{1}\left[\right.$ Gozde Inci $^{2}\left(\mathbb{D} \cdot\right.$ Ozlem Oyardi $^{1}$ (D) Paul B. Savage ${ }^{3}$ (i)
}

Received: 22 January 2020 / Accepted: 9 March 2020 / Published online: 18 March 2020

(c) Springer Science+Business Media, LLC, part of Springer Nature 2020

\begin{abstract}
Acinetobacter baumannii is an emerging opportunistic pathogen that primarily infects critically ill patients in nosocomial settings and there is a need for identifying new alternative therapeutic agents against these organisms. Ceragenins are nonpeptide, membrane-active agents that mimic the antimicrobial properties of antimicrobial peptides (AMPs) and affect the membrane permeability of microorganisms. The in vitro activities of CSA-8, CSA-13, CSA-44, CSA-131, CSA-138 either alone or in combination with colistin (sulphate) were determined against 25 carbapenem-resistant A. baumannii strains. Minimum inhibitory concentrations (MICs) and minimum bactericidal concentrations (MBCs) of selected ceragenins and colistin against these isolates were measured by in vitro microbroth dilution techniques. Checkerboard techniques and time-kill assays were performed to determine the activities of combinations. The MIC $_{50}$ values (mg/L) of CSA-8, CSA-13, CSA-44, CSA-131, CSA-138 and colistin were 32, 4, 8, 2, 4 and 0.5, respectively. The $\mathrm{MIC}_{90}(\mathrm{mg} / \mathrm{L})$ of CSA-8, CSA-13, CSA-44, CSA-131, CSA-138 and colistin were 128, 8, 16, 8, 16 and 16, respectively. At $6 \mathrm{~h}, 1 \times \mathrm{MIC}$ and $2 \times \mathrm{MIC}$ of CSA-13 were bactericidal. CSA-13 + colistin combination displayed synergistic interaction. Antagonism between antimicrobials was not observed. According to the results, CSA-13 and CSA-131 can be good alternatives for infections caused by carbapenemresistant A. baumannii.
\end{abstract}

\section{Introduction}

Acinetobacter baumannii is a ubiquitous Gram-negative opportunistic pathogen that is commonly associated with aquatic environments [1]. A. baumannii has emerged as a serious cause of nosocomial infections, especially among critically ill patients in intensive care units, causing ventilator-associated pneumonia (VAP), septicemia, secondary meningitis, endocarditis, infections of the skin, soft tissues, urinary tract and those originating from prosthetic devices [2]. Due to the rapid development of resistance to various antibiotics, only a few antibiotics provide effective treatment

Ozlem Oyardi

ozlemoyardi@istanbul.edu.tr

1 Department of Pharmaceutical Microbiology, Faculty of Pharmacy, Istanbul University, Istanbul, Turkey

2 Department of Biochemistry, College of Medicine, Hallym University, Gangwon-do, Chuncheon 200-702, South Korea

3 Department of Chemistry and Biochemistry, Brigham Young University, Provo, UT 84602, USA caused by this pathogen. For example, carbapenems have been one of the main antimicrobial classes used against $A$. baumannii infections, but the emergence and dissemination of carbapenemases have diminished the utility of this class of drugs from an already limited list of existing treatment options. In 2017, WHO published a list of antibiotic-resistant priority pathogens for which new antibiotics are urgently needed and the most critical group is carbapenem-resistant A. baumannii (CRAB). Among the alternatives for the treatment of infections due to CRAB, polymyxins and other non$\beta$-lactam agents may be valuable options [3-6].

Endogenous AMPs have been the subjects of extensive studies, in part due to their breadth of activity and the proposition that bacterial activities are unlikely to readily develop resistance. However, AMPs have disadvantages such as having complex structures, difficult synthesis and purification mechanisms, and short half-lives due to proteases [7, 8]. Ceragenins have been developed as a result of studies to develop non-peptide derivatives of AMPs and thus reduce their disadvantages [8]. Ceragenins, which are membrane active molecules, combine with the cell surfaces of microorganisms and cause depolarization and death. Only a few 
studies have been reported in which the potential activities of ceragenins CSA-13 and CSA-131 have been evaluated against $\mathrm{CRAB}$ alone or in combination with other antibiotics [10-16]. However, there are no published studies describing the activities of ceragenins CSA-8, CSA-44 and CSA-138 against CRAB.

To better understand the antibacterial activity of ceragenins against CRAB, we evaluated the antibacterial activities of CSA-8, CSA-13, CSA-44, CSA-131 and CSA-138 against clinical isolates of CRAB. We compared ceragenin activity with that of colistin as well as potential synergy in combination using both checkerboard and time-kill curve experiments.

\section{Material and Methods}

\section{Bacterial Strains}

A total of 25 (Ab-1, Ab-2...Ab-25) non-repeat CRAB strains were obtained from the Department of Infectious Diseases, Faculty of Cerrahpasa Medicine, Istanbul University. API 20 NE System (bioMerieux Vitek, Marcy l'Etoile, France) was used to identify strains. Strains were determined as carbapenem-resistant according to disc diffusion and microdilution methods. For combination time-kill experiments, four strains were used and Escherichia coli ATCC 25,922 (Rockville, Md., USA) was quality control strain.

\section{Antimicrobial Agents}

CSA-8, CSA-13, CSA-44, CSA-131 and CSA-138 (Fig. 6) were synthesized and provided by one of the authors (P.B.S.) [8]. Colistin and meropenem were obtained from SigmaAldrich and Astra Zeneca (Turkey), respectively. Stock solutions of ceragenins and colistin from dry powders were prepared in distilled water, stored frozen at $-80^{\circ} \mathrm{C}$ and used within 6 months. Meropenem was prepared on the day of use.

\section{Determinations of MICs and MBCs}

MICs and MBCs were determined by using the microbroth dilution method according to CLSI [17]. Serial twofold dilutions ranging from 128 to $0.06 \mathrm{mg} / \mathrm{L}$ of antimicrobials were prepared in the 96-well U-bottom microplates. The inoculum was added with a final concentration of $5 \times 10^{5} \mathrm{cfu} / \mathrm{mL}$. Microplates were incubated at $37^{\circ} \mathrm{C}$ for $18-20 \mathrm{~h}$. Experiments were done independently in duplicate. To determine MBCs, after incubation, $0.01 \mathrm{~mL}$ samples from each well where no growth was observed were taken and plated onto Tryptic soy agar (TSA). The lowest concentration of antibiotic giving at least a $99.9 \%$ killing of the initial inoculum was defined as the MBC [18].

\section{Determination of Fractional Inhibitory Concentration Index (FICI)}

The microbroth checkerboard technique was used to determine the effects of combinations [19]. A mixture of different concentrations of the antibiotics was added to the 96-well U-bottom microplates and inoculated with a final concentration of approximately $5 \times 10^{5} \mathrm{cfu} / \mathrm{mL}$ of inoculum. After incubation at $37^{\circ} \mathrm{C}$ for $18-20 \mathrm{~h}$, the fractional inhibitory concentration index (FICI) was determined as the sum of concentrations of the antimicrobials required for growth inhibition divided by the MICs of the antimicrobials. After incubation, FIC was determined and FIC of $\leq 0.5$ was defined as synergism, FIC of $>0.5-4$ as no interaction and FIC of 4.0 as antagonism [20].

\section{Time-Kill Assays}

Time-kill assays were performed on four CRAB strains (Ab$3, \mathrm{Ab}-9, \mathrm{Ab}-13, \mathrm{Ab}-23)$. Tubes containing freshly prepared cation-adjusted Mueller-Hinton broth supplemented with the drug were inoculated with $A$. baumannii isolates to a density of $10^{6} \mathrm{cfu} / \mathrm{mL}$ in a final volume of $20 \mathrm{~mL}$ and incubated in a shaking bath at $37^{\circ} \mathrm{C}$. Aliquots were removed at time $0,1,2$, 4,6 and $24 \mathrm{~h}$ post inoculation and serially diluted in saline for determination of viable counts. Diluted samples $(10 \mu \mathrm{L})$ were plated on TSA plates, and bacterial counts were determined after $18 \mathrm{~h}$ of incubation at $37^{\circ} \mathrm{C}$. Concentrations of antimicrobial agents used were at $0.5 \times \mathrm{MIC}, 1 \times \mathrm{MIC}$ and $2 \times \mathrm{MIC}$ alone, or in combination. The bactericidal activity was defined as a $3 \log 10 \mathrm{cfu} / \mathrm{mL}$ reduction in the colony count, relative to the initial inoculum. Synergy and indifference were, respectively, defined as $a \geq 2 \log 10$ and $<2 \log 10$ decrease in the cfu count when the combination was compared with the most active single drug after $24 \mathrm{~h}$ of incubation [18]. Experiments were performed independently in duplicate. The limit of detection (LOD) was $\leq 1.3 \log _{10} \mathrm{cfu} / \mathrm{mL}$. The mean $\mathrm{cfu} / \mathrm{mL}$ values for the bacteria were also compared between groups for each antibiotic alone or in combination. Statistical analysis for the comparison of each combination was performed using one-way Anova test - the non-parametric analysis of variance - and Bonferroni correction for post hoc comparisons. Any value of $P$ below 0.05 was considered as statistically significant.

\section{Results and Discussion}

\section{Susceptibility}

MICs and MBCs of CSA-8, CSA-13, CSA-44, CSA-131, CSA-138, colistin and meropenem were determined and 
Table 1 MIC and MBC values (mg/L) of antimicrobial agents against 25 clinical CRAB strains

\begin{tabular}{llll}
\hline Antimicrobials & $\begin{array}{l}\text { MICrange/MBC } \\
\text { range }\end{array}$ & MIC50/MBC50 & MIC90/MBC90 \\
\hline CSA-8 & $16-128 / 32-128$ & $32 / 32$ & $128 / 128$ \\
CSA-13 & $1-16 / 2-16$ & $4 / 4$ & $8 / 32$ \\
CSA-44 & $8-16 / 16-32$ & $8 / 8$ & $16 / 32$ \\
CSA-131 & $1-8 / 2-16$ & $2 / 4$ & $8 / 16$ \\
CSA-138 & $4-32 / 4-32$ & $4 / 4$ & $16 / 16$ \\
Colistin & $0.125-4 / 0.5-4$ & $0.5 / 1$ & $4 / 4$ \\
Meropenem & $8-128 / 8-256$ & $16 / 32$ & $32 / 64$ \\
\hline
\end{tabular}



Fig. 1 Percentage distribution of MIC value of tested antimicrobials

summarized in Table 1 and Fig. 1 . All the strains were resistant to meropenem.

\section{Checkerboard}

In vitro activities of CSAs combined with colistin or CSAs against CRAB are shown in Tables 2, 3. CSA-13 + colistin, CSA-13 + CSA-131, CSA-13 + CSA-138 and CSA$131+$ CSA-138 combinations were determined as synergistic because their FIC indexes were less than 0.5. However, additive effects were detected in all combinations. Any combination did not show any antagonistic interaction.

\section{Time-Kill Assays}

Time-kill assays were performed on four isolates with colistin, CSA-13 and CSA-131 to observe their behaviours alone and in combinations and the results are given in Table 4 and Figs. 2, 3, 4, 5. Concentrations of $1 \times \mathrm{MIC}$ and $2 \times \mathrm{MIC}$ of CSA-13 were bactericidal along the curve at $6 \mathrm{~h}$, with re-growth being observed at $24 \mathrm{~h}$. In addition to this, earlier bactericidal effects were documented at the end of $2 \mathrm{~h}$ and $4 \mathrm{~h}$ with colistin, CSA-13 and CSA-131. In combination
Table 2 In vitro activity of CSA-13, CSA-131, CSA-138 combined with colistin against $\mathrm{CRAB}$ by using the microbroth checkerboard technique

\begin{tabular}{llll}
\hline Antimicrobials & $\mathrm{N}$ & $\begin{array}{l}\text { Synergistic } \\
\text { effects FIC 0.5 }\end{array}$ & $\begin{array}{l}\text { Addi- } \\
\text { tive effects } \\
\text { FIC }>0.5-4.0\end{array}$ \\
\hline Colistin + CSA-13 & 7 & 1 & 6 \\
Colistin + CSA-131 & 2 & 0 & 2 \\
Colistin + CSA-138 & 2 & 0 & 2 \\
\hline
\end{tabular}

Table 3 In vitro activity of some CSA molecules combined with CSA molecules against CRAB by using the microbroth checkerboard technique

\begin{tabular}{llll}
\hline Antimicrobials & N & $\begin{array}{l}\text { Synergistic } \\
\text { effects FIC 0.5 }\end{array}$ & $\begin{array}{l}\text { Addi- } \\
\text { tive effects } \\
\text { FIC }>0.5-4.0\end{array}$ \\
\hline CSA-13+CSA-131 & 7 & 1 & 6 \\
CSA-13+CSA-138 & 2 & 1 & 1 \\
CSA-131+CSA-138 & 5 & 1 & 4 \\
\hline
\end{tabular}

time-kill studies, CSA-13 + colistin combination demonstrated synergistic activity against two of four strains at $0.5 \times \mathrm{MIC}$ and $1 \times \mathrm{MIC}$ and against one of four strains at $2 \times$ MIC. CSA-131 + colistin combination demonstrated synergistic activity against two of four strains at $1 \times \mathrm{MIC}$ and against one of four strains at $2 \times$ MIC. CSA- $13+$ CSA- 131 combination demonstrated synergistic activity against one of four strains at $1 \times \mathrm{MIC}$ and against two of four strains at $2 \times$ MIC. Earlier synergistic effects were noted at 2, 4 and $6 \mathrm{~h}$.

Recently, outbreaks caused by resistant $A$. baumannii have been reported in Turkey as well as in all parts of the World [21-23]. In the past decade, there has been a dramatic increase in CRAB [22]. Therefore, in order to take the microorganism under control, selection of the antimicrobial agents is extremely important. Ceragenins are a group of cholic acid derivatives that have potent activities against various microorganisms. Recently, it is documented that CSA-13 and CSA-131 are active both against colistin-resistant and carbapenem-resistant $A$. baumannii strains [9-16]. Villa-Farres et al. showed that CSA-13 and CSA-131 showed good activity against resistant- $A$. baumannii, with a $2 \mathrm{mg} / \mathrm{L}$ of $\mathrm{MIC}_{50}$ value [16]. In this study, the $\mathrm{MIC}_{50}$ values of the studied antibiotics were ranked as follows: colistin $>$ CSA$131>$ CSA-13 $=$ CSA $-138>$ CSA- $44>$ CSA- 8 . It is thought that CSA-131 has the best activity because it has long hydrophobic chain at $\mathrm{C} 12$ carbon (Fig. 6). The MICs and MBCs of the CSA-13 and CSA-131 are closer to those of colistin. The current results are similar to those reported by BozkurtGuzel et al. [9] and Villa-Farres et al. [16] Regarding all tested CSAs, the results obtained reaffirm the good activity 
Table 4 Extent of bacterial killing exerted by antibiotics alone and in combination (time-kill curve) over time against CRAB clinical strains

\begin{tabular}{|c|c|c|c|c|c|c|c|c|c|c|c|c|c|c|c|}
\hline \multirow{3}{*}{$\begin{array}{l}\text { Antibiotics and con- } \\
\text { centrations }(\mathrm{mg} / \mathrm{L})\end{array}$} & \multicolumn{15}{|c|}{ No. of isolates showing the following $\log 10 \mathrm{cfu} / \mathrm{ml}$ decrease at the designated incubation time } \\
\hline & \multicolumn{3}{|l|}{ 1.h } & \multicolumn{3}{|l|}{ 2.h } & \multicolumn{3}{|c|}{ 4. h } & \multicolumn{3}{|l|}{$6 . \mathrm{h}$} & \multicolumn{3}{|c|}{ 24.h } \\
\hline & -1 & -2 & -3 & -1 & -2 & -3 & -1 & -2 & -3 & -1 & -2 & -3 & -1 & -2 & -3 \\
\hline \multicolumn{16}{|l|}{ CSA- $13^{\mathrm{a}}$} \\
\hline $0.5 \times \mathrm{MIC}$ & 2 & 0 & 0 & 3 & 1 & 0 & 0 & 3 & 1 & 1 & 0 & 0 & 0 & 0 & 0 \\
\hline $1 \times \mathrm{MIC}$ & 4 & 0 & 0 & 1 & 2 & 1 & 0 & 1 & 3 & 0 & 3 & 1 & 0 & 0 & 0 \\
\hline $2 \times \mathrm{MIC}$ & 3 & 1 & 0 & 0 & 2 & 2 & 0 & 0 & 4 & 0 & 3 & 1 & 0 & 0 & 0 \\
\hline \multicolumn{16}{|l|}{ CSA-131 ${ }^{a}$} \\
\hline $0.5 \times \mathrm{MIC}$ & 3 & 0 & 0 & 1 & 3 & 0 & 0 & 4 & 0 & 4 & 0 & 0 & 0 & 0 & 0 \\
\hline $1 \times \mathrm{MIC}$ & 4 & 0 & 0 & 0 & 4 & 0 & 0 & 4 & 0 & 3 & 1 & 0 & 0 & 0 & 0 \\
\hline $2 \times \mathrm{MIC}$ & 3 & 1 & 0 & 0 & 0 & 4 & 0 & 0 & 3 & 0 & 4 & 0 & 0 & 0 & 0 \\
\hline \multicolumn{16}{|l|}{ Colistin $^{\mathrm{a}}$} \\
\hline $0.5 \times \mathrm{MIC}$ & 1 & 0 & 0 & 3 & 1 & 0 & 0 & 4 & 0 & 3 & 1 & 0 & 0 & 0 & 0 \\
\hline $1 \times \mathrm{MIC}$ & 4 & 0 & 0 & 0 & 3 & 1 & 0 & 1 & 2 & 0 & 4 & 0 & 0 & 0 & 0 \\
\hline $2 \times \mathrm{MIC}$ & 3 & 0 & 0 & 0 & 3 & 1 & 0 & 1 & 1 & 0 & 4 & 0 & 0 & 0 & 0 \\
\hline \multicolumn{16}{|l|}{ CSA $-13+$ Colistin $^{\text {b }}$} \\
\hline $0.5 \times \times \mathrm{MIC}$ & 1 & 0 & 0 & 2 & 0 & 0 & 1 & 1 & 0 & 3 & 0 & 0 & 2 & 1 & 1 \\
\hline $1 \times \mathrm{MIC}$ & 1 & 2 & 0 & 4 & 0 & 0 & 3 & 1 & 0 & 3 & 1 & 0 & 2 & 2 & 0 \\
\hline $2 \times \mathrm{MIC}$ & 3 & 1 & 0 & 2 & 2 & 0 & 4 & 0 & 0 & 4 & 0 & 0 & 3 & 1 & 0 \\
\hline \multicolumn{16}{|l|}{ CSA-131+ Colistin ${ }^{b}$} \\
\hline $0.5 \times \mathrm{MIC}$ & 0 & 0 & 0 & 2 & 1 & 0 & 3 & 1 & 0 & 4 & 0 & 0 & 4 & 0 & 0 \\
\hline $1 \times \mathrm{MIC}$ & 1 & 0 & 0 & 1 & 0 & 0 & 3 & 0 & 0 & 4 & 0 & 0 & 2 & 2 & 0 \\
\hline $2 \times \mathrm{MIC}$ & 1 & 0 & 0 & 1 & 0 & 0 & 4 & 0 & 0 & 3 & 1 & 0 & 3 & 1 & 0 \\
\hline \multicolumn{16}{|l|}{ CSA $-13+$ CSA $131^{b}$} \\
\hline $0.5 \times \mathrm{MIC}$ & 0 & 0 & 0 & 2 & 0 & 0 & 3 & 1 & 0 & 4 & 0 & 0 & 3 & 1 & 0 \\
\hline $1 \times \mathrm{MIC}$ & 1 & 0 & 0 & 1 & 0 & 0 & 1 & 1 & 1 & 4 & 0 & 0 & 4 & 0 & 0 \\
\hline $2 \times \mathrm{MIC}$ & 1 & 0 & 0 & 3 & 0 & 0 & 3 & 0 & 0 & 4 & 0 & 0 & 2 & 2 & 0 \\
\hline
\end{tabular}

${ }^{a}$ Bactericidal activity was defined as a $\geq 3-\log 10 \mathrm{cfu} / \mathrm{ml}$ decrease from the initial inoculum

${ }^{\mathrm{b}}$ Synergy was defined as a 100 -fold increase in colony count at $24 \mathrm{~h}$ by the combination compared with the most active agent alone

of these compounds except CSA-8 against CRAB, highlighting CSA-13 and CSA-131 as the best compounds, with lower MICs against all of the strains (Table 1). We found the highest MIC results with CSA-8. MIC ranges of CSA-44 and CSA-138 are almost the same. Our study also shows that CSA-13, CSA-44 and CSA-138 have an $\mathrm{MIC}_{50} / \mathrm{MBC}_{50}$ ratio of 1 , suggesting that the bactericidal activity is close to the inhibitory concentration.

Furthermore, according to time-kill assay, concentrations of $1 \times \mathrm{MIC}$ and $2 \times \mathrm{MIC}$ of CSA-13 were bactericidal along the curve at $6 \mathrm{~h}$, with re-growth being observed at $24 \mathrm{~h}$. In addition to this, earlier bactericidal effects were documented at the end of $2 \mathrm{~h}$ and $4 \mathrm{~h}$ with colistin, CSA-13 and CSA- 131 .

In checkerboard, different effects were observed with additive effect being the most frequent interaction between colistin + CSA-13 and CSA-13 + CSA-131 combinations (Tables 2, 3). Colistin + CSA-13 was synergistic with one of the seven strains and showed an additive effect with the remaining strains. A synergistic effect was observed for CSA-13 + CSA-131, CSA-13 + CSA-138 and CSA$131+$ CSA-138 combinations. Notably, an antagonistic effect was never detected. In the literature, combinations of CSA-13-colistin have previously been reported to be synergistic against CRAB [9], which is in line with our results.

The results of combination time-kill assay showed that not only, $2 \times$ MIC combinations of CSA- $13+$ colistin are synergistic, but also $0.5 \times \mathrm{MIC}$ combinations are synergistic. In CSA-131 + colistin combination, synergistic activities are determined when the agents are used at $1 \times$ MIC or $2 \times$ MIC. CSA-13 + CSA-131 combination demonstrated synergistic 
Fig. 2 Time-kill assays for CSAs and colistin alone and in combination against Acb- 3 . a $0.5 \times \mathrm{MIC}$, b $1 \times \mathrm{MIC}$ c $2 \times \mathrm{MIC}$.

The $\mathrm{X}$-axis represents the killing time, and the Y-axis represents the logarithmic bacterial survival. Error bars indicate standard deviation. cfu: colonyforming units
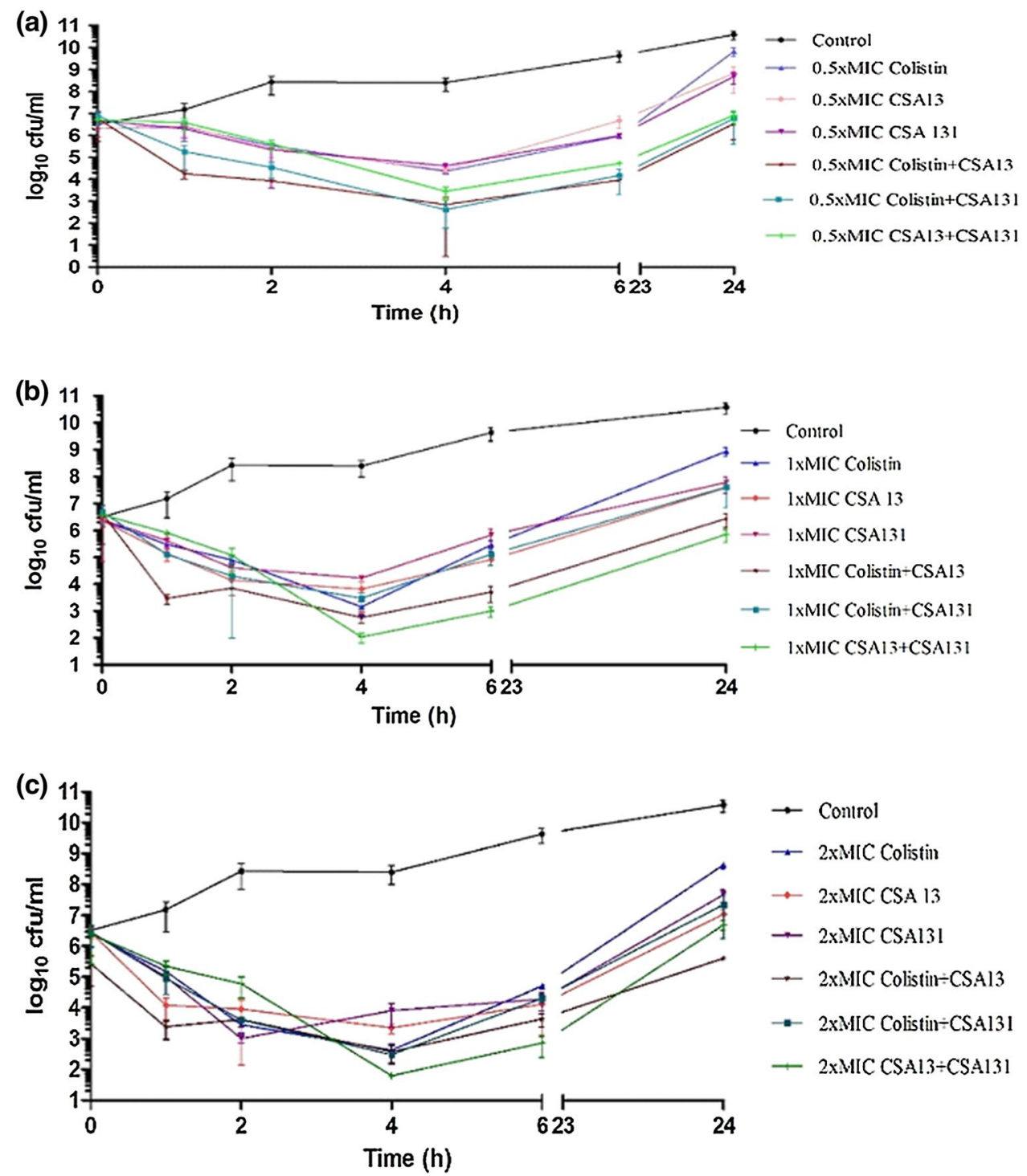

activity against one of four strains at $1 \times \mathrm{MIC}$ and against two of four strains at $2 \times \mathrm{MIC}(\mathrm{p}<0.05)$. Earlier synergistic effects were noted at 2, 4 and $6 \mathrm{~h}$.

According to these combination results, it seems to be promising to combine CSA-13, CSA-131 and colistin where antibacterial agents provide a bactericidal effect in a concentration-dependent manner. Ceragenins can increase susceptibility to antimicrobials by affecting the permeability of both the outer membrane and cytoplasmic membrane of Gram-negative bacteria [12]. The findings of the study extend current knowledge on synergistic activity of CSA-13 and CSA-131 in combination with colistin and support the potential role of CSAs as a novel therapeutic agent against CRAB. 
Fig. 3 Time-kill assays for CSAs and colistin alone and in combination against Acb-9. a $0.5 \times \mathrm{MIC}$, b $1 \times \mathrm{MIC}$ c $2 \times \mathrm{MIC}$. The $\mathrm{X}$-axis represents the killing time, and the Y-axis represents the logarithmic bacterial survival. Error bars indicate standard deviation. cfu: colonyforming units
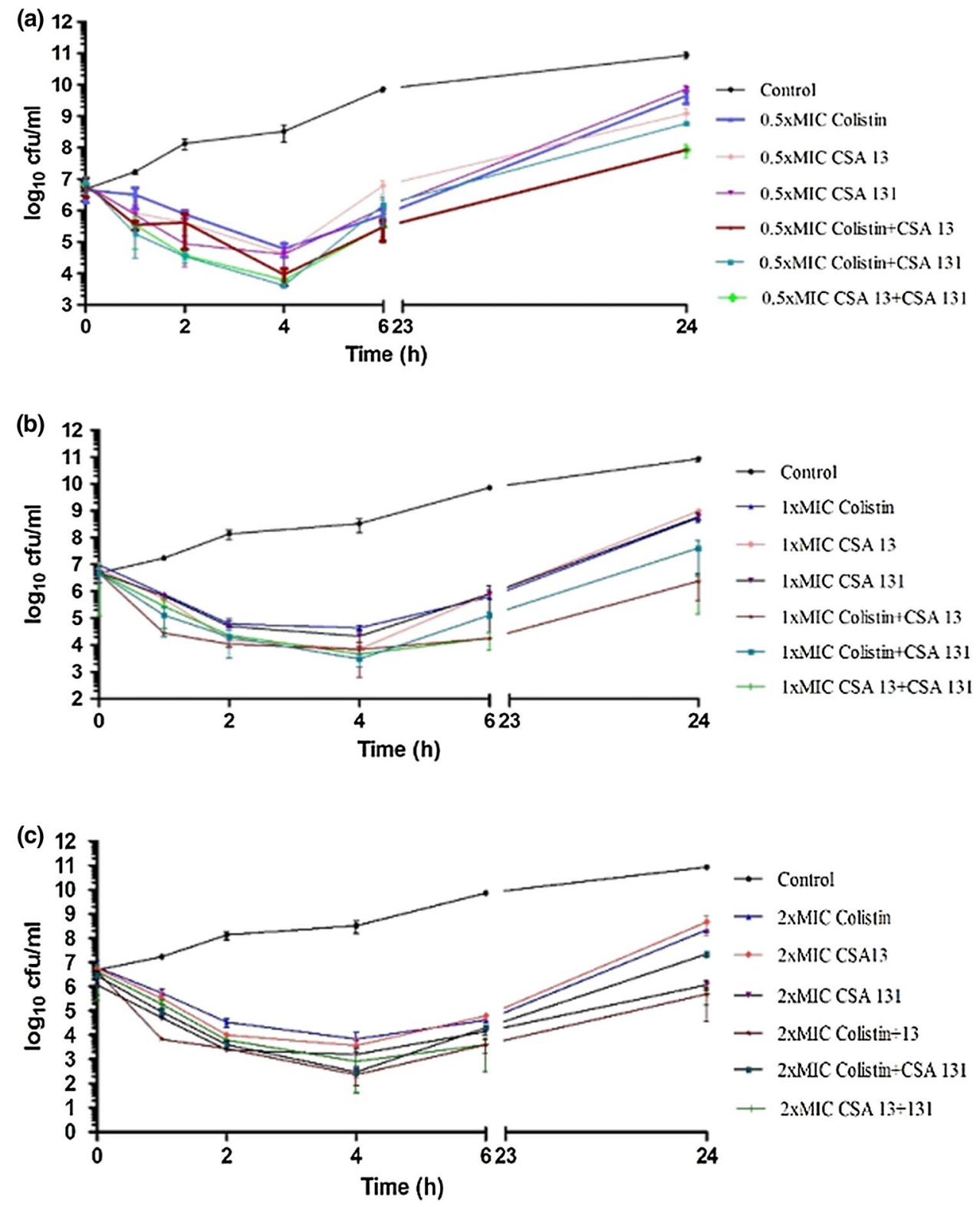
Fig. 4 Time-kill assays for CSAs and colistin alone and in combination against Acb-13. a $0.5 \times \mathrm{MIC}, \mathbf{b} 1 \times \mathrm{MIC}$ c $2 \times \mathrm{MIC}$.

The $\mathrm{X}$-axis represents the killing time, and the Y-axis represents the logarithmic bacterial survival. Error bars indicate standard deviation. cfu: colonyforming units

Fig. 5 Time-kill assays for CSAs and colistin alone and in combination against to Acb23. a $0.5 \times \mathrm{MIC}, \mathbf{b} 1 \times \mathrm{MIC}$ c $2 \times$ MIC. The $\mathrm{X}$-axis represents the killing time, and the $\mathrm{Y}$-axis represents the logarithmic bacterial survival. Error bars indicate standard deviation. cfu: colony-forming units
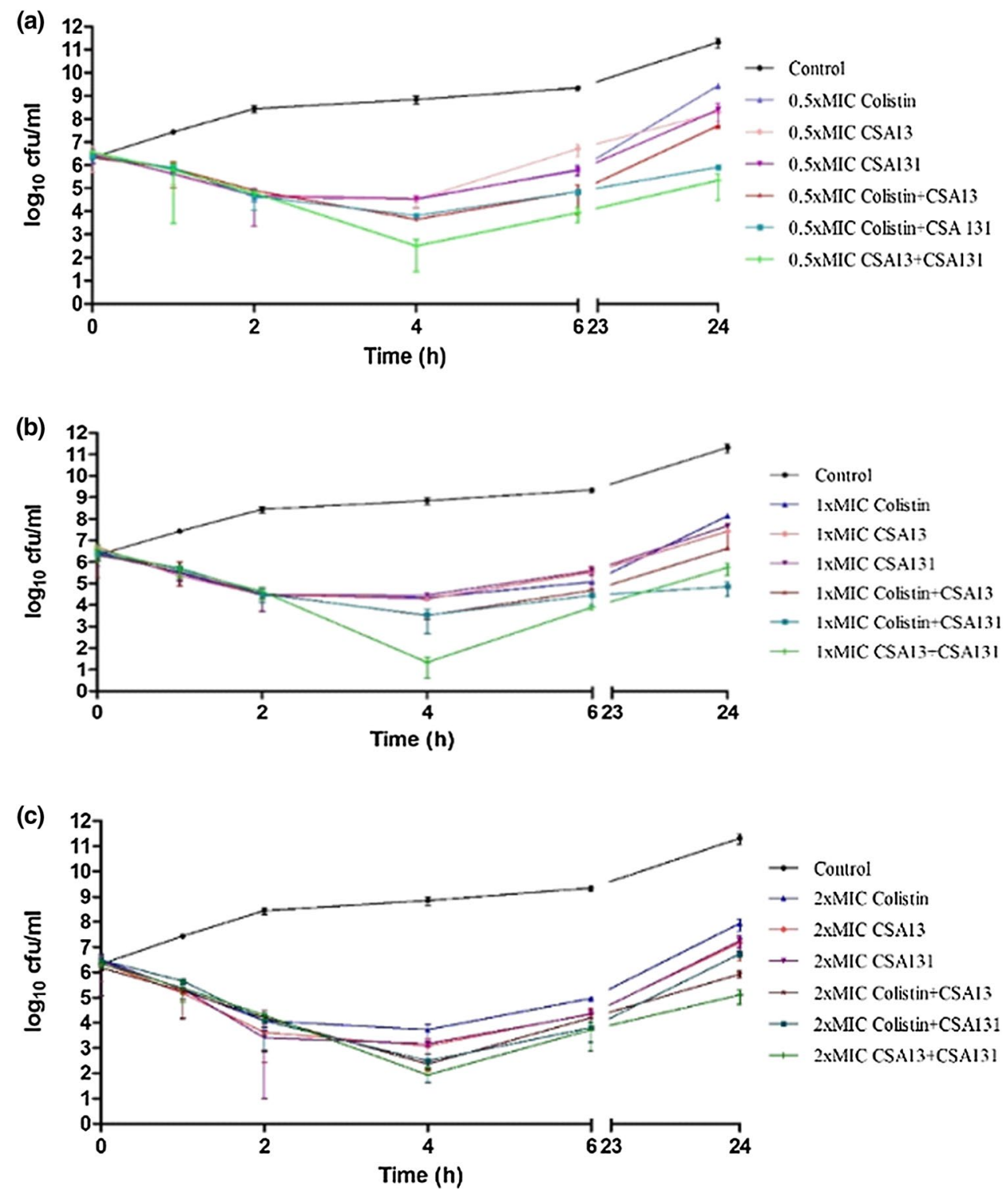




CSA 8

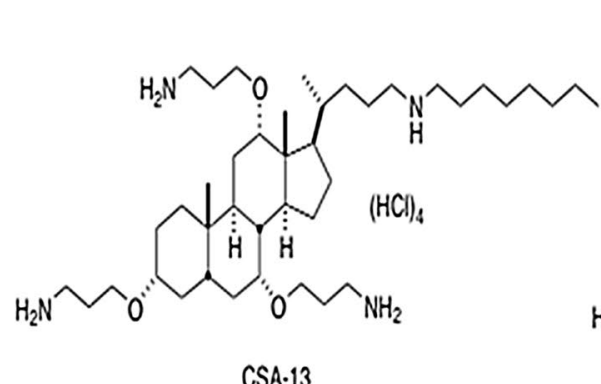

CSA-13



CSA.44

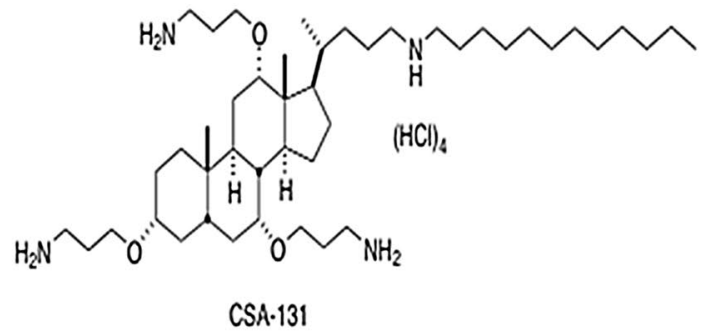



Fig. 6 The structure of ceragenins used in the present study

Acknowledgements This work was supported by grant from Scientific Research Projects Unit, Istanbul University (Grant No. 52623). We thank the Department of Infectious Diseases, Faculty of Cerrahpasa Medicine, Istanbul University for providing us with all isolates.

Author Contributions CBG designed the experiments, carried out the study, interpreted the data and drafted the manuscript. GI carried out the experiments, interpreted the data. PBS and OO supervised all experiments and reviewed the manuscript.

\section{Compliance with Ethical Standards}

Conflict of interest The authors declare that they have no conflict of interest for this study.

\section{References}

1. Chittawatanarat K, Jaipakdee W, Chotirosniramit N, Chandacham K, Jirapongcharoenlap T (2014) Microbiology, resistance patterns, and risk factors of mortality in ventilator-associated bacterial pneumonia in a Northern Thai tertiary-care university based general surgical intensive care unit. Infect Drug Resist 7:203-210. https://doi.org/10.2147/IDR.S67267

2. Chen CH, Lin LC, Chang YJ, Chen YM, Chang CY, Huang CC (2015) Infection control programs and antibiotic control programs to limit transmission of multi-drug resistant Acinetobacter baumannii infections: evolution of old problems and new challenges for institutes. Int J Environ Res Public Health 12:8871-8882. https ://doi.org/10.3390/ijerph120808871

3. Krol V, Hamid NS, Cunha BA (2009) Neurosurgically related nosocomial Acinetobacter baumannii meningitis: report of two cases and literature review. J Hosp Infect 71:176-180. https://doi. org/10.1016/j.jhin.2008.09.018

4. Karageorgopoulos DE, Falagas ME (2008) Current control and treatment of multidrug-resistant Acinetobacter baumannii infections. Lancet Infect Dis 8:751-762. https://doi.org/10.1016/ S1473-3099(08)70279-2

5. Evans BA, Amyes SG (2014) OXA beta-lactamases. Clin Microbiol Rev 27:241-263. https://doi.org/10.1128/CMR.00117-13

6. World Health Organization (WHO). Global Priority List of Antibiotic-Resistant Bacteria to Guide Research, Discovery, and Development of New Antibiotics. https://www.who.int/medicines/ publications/WHO-PPL-Short_Summary_25Feb-ET_NM_WHO. pdf?ua $=1$. Accessed 7 February 2018

7. Hadley EB, Hancock RE (2010) Strategies for the discovery and advancement of novel cationic antimicrobial peptides. Curr Top Med Chem 10:1872-1881. https://doi.org/10.2174/1568026107 93176648

8. Lai XZ, Feng Y, Pollard J, Chin JN, Rybak MJ, Bucki R, Epand RF, Epand RM, Savage PB (2008) Ceragenins: cholic acid-based mimics of antimicrobial peptides. Acc Chem Res 41:1233-1240. https://doi.org/10.1021/ar700270t

9. Bozkurt-Guzel C, Savage PB, Akcali A, Ozbek-Celik B (2014) Potential synergy activity of the novel ceragenin, CSA-13, against carbapenem-resistant Acinetobacter baumannii strains isolated from bacteremia patients. BioMed Res Int 2014:710273. https:// doi.org/10.1155/2014/710273

10. Bozkurt-Guzel C, Savage PB, Gerceker AA (2011) In vitro activities of the novel ceragenin CSA-13, alone or in combination with colistin, tobramycin, and ciprofloxacin, against Pseudomonas aeruginosa strains isolated from cystic fibrosis patients. Chemotherapy 57:505-510. https://doi.org/10.1159/000335588

11. Bucki R, Niemirowicz K, Wnorowska U, Byfield FJ, Piktel E, Watek M, Janmey PA, Savage PB (2015) Bactericidal activity of ceragenin CSA-13 in cell culture and in an animal model of peritoneal infection. Antimicrob Agents Chemother 59:6274-6282. https://doi.org/10.1128/AAC.00653-15

12. Chin JN, Rybak MJ, Cheung CM, Savage PB (2007) Antimicrobial activities of ceragenins against clinical isolates of resistant Staphylococcus aureus. Antimicrob Agents Chemother 51:1268-1273. https://doi.org/10.1128/AAC.01325-06

13. Howell MD, Streib JE, Kim BE, Lesley LJ, Dunlap AP, Geng D, Feng Y, Savage PB, Leung DY (2009) Ceragenins: a class 
of antiviral compounds to treat orthopox infections. J Invest Dermatol 129:2668-2675. https://doi.org/10.1038/jid.2009.120

14. Leszczynska K, Namiot D, Byfield FJ, Cruz K, ZendzianPiotrowska M, Fein DE, Savage PB et al (2013) Antibacterial activity of the human host defence peptide LL-37 and selected synthetic cationic lipids against bacteria associated with oral and upper respiratory tract infections. J Antimicrob Chemother 68:610-618. https://doi.org/10.1093/jac/dks434

15. Lara D, Feng Y, Bader J, Savage PB, Maldonado RA (2010) Anti-trypanosomatid activity of ceragenins. J Parasitol 96:638642. https://doi.org/10.1645/GE-2329.1

16. Vila-Farres X, Callarisa AE, Gu X, Savage PB, Giralt E, Vila J (2015) CSA-131- a ceragenin active against colistin-resistant Acinetobacter baumannii and Pseudomonas aeruginosa clinical isolates. Int J Antimicrob Agents 46:568-571. https://doi. org/10.1016/j.ijantimicag.2015.08.003

17. Clinical and Laboratory Standards Institute (2015) Performance standards for antimicrobial susceptibility testing. Twenty-fifth Informational Supplement M100-S25. CLSI, Wayne, PA, USA

18. National Committee for Clinical Laboratory Standards (1999) Methods for determining bactericidal activity of antimicrobial agents - approved guideline M26-A. NCCLS, Wayne, PA, USA

19. Pillai SK, Moellering RC Jr, Eliopoulos GM (2005) Antimicrobial combinations. In: Lorian V (ed) Antibiotics in laboratory medicine, 5th edn. Lippincott Williams and Wilkins, Philadelphia, USA, pp 365-440
20. Odds FC (2003) Synergy, antagonism, and what the chequerboard puts between them. J Antimicrob Chemother 52:1. https://doi. org/10.1371/journal.pone.0052503

21. Ulu-Kilic A, Gundogdu A, Cevahir F, Kilic H, Gunes T, Alp E (2018) An outbreak of bloodstream infection due to extensively resistant Acinetobacter baumannii among neonates. Am J Infect Control 46(2):154-158. https://doi.org/10.1016/j.ajic.2017.08.007

22. Seifert H, Stefanik D, Sutcliffe JA, Higgins PA (2018) In-vitro activity of the novel fluorocycline eravacycline against carbapenem non-susceptible Acinetobacter baumannii. Int J Antimicrob Agents 51(1):62-64. https://doi.org/10.1016/j.ijantimica g.2017.06.022

23. Tomaschek F, Higgins PG, Stefanik D, Wisplinghoff H, Seifert H (2016) Head-to-Head Comparison of two multi-locus sequence typing (MLST) schemes for characterization of Acinetobacter baumannii outbreak and sporadic isolates. PLoS ONE 11:e0153014. https://doi.org/10.1371/journal.pone.0153014

Publisher's Note Springer Nature remains neutral with regard to jurisdictional claims in published maps and institutional affiliations. 